valid reason for attendance at a clinic? Assessment of menstrual complaints needs to be improved, and further research is required to understand the part played by the cultural beliefs of both women and clinicians. The comorbidity of menstrual complaints shows that the conventional partitioned thinking about menstrual problems will be unhelpful in most cases.

We thank the study research nurses Elaine Kacser and Dorothy Lyons, Robbie Foy for discussions about the findings, and the participants.

Contributors: PW had the original idea for the study and design and led the funding application, study execution, and analysis and preparation of the manuscript. She will act as guarantor for the paper. HOCD and MAL were coapplicants for funding. PW sought ethical approval in Edinburgh and MAL in Glasgow. HODC, MAL, MCB, and AD contributed to the design, management of the study, and preparation of the manuscript. $\mathrm{AD}$ coordinated data management. GM contributed to the analysis, interpretation, and writing.

Funding: This research was made possible by a three year grant from the Chief Scientist's Office, Scotland (K/MRS/50/ C2472)

Competing interests: None declared.

1 Royal College of General Practitioners, Office of Population Censuses and Surveys, Department of Health. 1981-1982 Morbidity statistics from general practice. Third national study: socio-economic analysis, Series 5. London: HMSO, 1990.

2 Bradlow J, Coulter A, Brooks P. Patterns of referral. Oxford: Oxford Health Services Research Unit, 1992.

NHS Dissemination Centre. The management of menorrhagia. Effect Healthcare Bull 1995;9.

4 Stirrat GM. Choice of treatment for menorrhagia. Lancet 1999;353: 2175-6.

5 MORI. Women's health in 1990. Market Opinion and Research International, 1990. (Research study conducted on behalf of Parke-Davis Laboratories.
6 Warner P. Preferences regarding treatments for period problems: relationship to menstrual and demographic factors. J Psychosom Obstet Gynaecol 1994;15:93-110.

7 Coulter A, McPherson K, Vessey M. Do British women undergo too many or too few hysterectomies? Soc Sci Med 1998;27:987-94.

8 Coulter A, Bradlow J, Agass M, Martin-Bates C, Tulloch A. Outcomes of referrals to gynaecology out-patients clinics for menstrual problems: an audit of general practice records. Br J Obstet Gynaecol 1991;98:789-96.

9 Carstairs V, Morris R. Deprivation and health in Scotland. Aberdeen: Aberdeen University Press, 1991

10 Fraser IS. Menorrhagia-a pragmatic approach to the understanding of causes and the need for investigations. $\mathrm{Br} J$ Obstet Gynaecol 1994;101(suppl 11):3-7.

11 Royal College of Obstetricians and Gynaecologists. The initial management of menorrhagia. Evidence-based clinical guidelines, No 1. London, RCOG 1998

12 Prentice A. Medical management of menorrhagia. BMJ 1999;319:1343-5.

13 Bonnar J, Sheppard BL. Treatment of menorrhagia during menstruation: randomised controlled trial of ethamsylate, mefenamic acid, and tranexamic acid. $B M J 1996 ; 313: 579-82$

14 Fraser IS, McCarron G, Markham R. A preliminary study of factors influencing perception of menstrual blood loss volume. Am J Obstet Gynecol 1984;149:788-93.

15 Gannon MJ, Day P, Hammadieh N, Johnson N. A new method for measuring menstrual blood loss and its use in screening women before endometrial ablation. Br J Obstet Gynaecol 1996;103:1029-33.

16 O'Flynn N, Britten N. Menorrhagia in general practice-disease or illness? Soc Sci Med 2000;50:651-61.

17 Thomas SL, Ellertson C. Nuisance or natural and healthy: should monthly menstruation be optional for women? Lancet 2000;355:922-4.

18 Scambler A, Scambler G. Menstrual symptoms, attitudes and consulting behaviour. Soc Sci Med 1985;20:1065-8.

19 Hutchison A. Explaining referral variation. BMJ 1993;307:1439.

20 Barry CA, Bradley CP, Britten N, Stevenson FA, Barber N. Patients' unvoiced agendas in general practice consultations: qualitative study. BMJ 2000;320:1246-50.

21 Grant C, Gallier L, Fahey T, Pearson N, Sarangi J. Management of menorrhagia in primary care-impact on referral and hysterectomy: data from the Somerset Morbidity Project. J Epidemiol Community Health 2000;54:709-13.

(Accepted 22 March 2001)

\title{
Primary care groups Progress in partnerships
}

\author{
Caroline Glendinning, Anna Coleman, Cathy Shipman, Gill Malbon
}

\section{This is the fourth in a series of five articles}

National Primary Care Research and Development Centre, University of Manchester, Manchester M13 9PL

Caroline Glendinning professor of social policy

Anna Coleman research fellow

continued over

BMJ 2001;323:28-3
Partnership-between organisations, services, and frontline staff-is widely promoted as an alternative to large scale structural reorganisation of the relation between the NHS and local government. However, there is still relatively little evidence on the effectiveness and outcomes of such partnerships. One of the difficulties in establishing an evidence base is the wide variety of relationships that can be described as partnerships. A second difficulty is the risk that working in partnership may be regarded as an end in itself rather than as the means to an end. The Audit Commission identified four potential areas of focus for groups working in partnership in public services (box). ${ }^{1}$ However, implementing these activities and measuring progress is far from easy.

The Health Act 1999 imposed a duty on all NHS organisations to work in partnership. Nowhere has working in partnership been given more backing than in the relations between the NHS and local authorities, where collaboration is required to tackle "wicked issues"1-that is, complex problems like health improvement, community safety, and community care. Primary care groups and trusts are required to give priority to forming partnerships with local authorities' social services departments, especially in developing services

\section{Summary points}

Primary care groups and trusts are expected to develop partnerships with local authorities, particularly for commissioning services and developing services for older people

Nearly half of the groups and trusts surveyed do not routinely consult with social services when commissioning community health services, and even fewer consult with social services about commissioning acute care

Relationships between frontline social services staff and community based and practice based health professionals are improving

The development of robust partnerships may be threatened by disruption to established relations as primary care groups merge or become trusts

for older people. In its plan for the NHS in England, the government announced that additional financial 
Areas of focus for groups working in partnership $^{1}$

- Develop a vision for a community

- Formulate strategic objectives

- Plan activities to meet agreed strategic objectives

- Manage joint operations

incentives for encouraging joint working would be available, particularly for developing intermediate care services, through a national performance fund. ${ }^{2}$

The government anticipates that primary care trusts will work increasingly with social services departments to commission integrated health and social care services for older people and people with mental health problems using new powers in the Health Act. These "flexibilities" relax previous legal duties and allow health and local authority organisations to pool budgets for specific services, delegate responsibility for commissioning services to a single "lead" organisation, and integrate the provision of health and social care. Furthermore, the care trusts proposed in the NHS plan, which will be able to commission and provide integrated services, ${ }^{2}$ will have equal representation from NHS and local authority partners on their boards. Where collaboration between primary care groups or trusts and local authorities is judged to be ineffective, powers in the Health and Social Care Bill 2000-2001 allow the Secretary of State to require the use of pooled budgets, lead commissioning, and integrated provider flexibilities to improve the integration of services.

These developments are expected to follow a tight time scale at a time of extensive organisational change-that is, as primary care groups are merging and becoming trusts and as local authorities are creating new cabinets and executive structures. These changes may disrupt emerging interagency partnerships and collaborations particularly in cases in which structural reorganisation is accompanied by changes in boundaries. Furthermore, the experience of collaborative activity in primary care is limited because joint planning and commissioning has previously been the responsibility or health authorities. ${ }^{34}$

We discuss the progress made by primary care groups and trusts in developing partnerships with their counterparts, their local authorities. A later paper in this series describes how the health improvement strategies of groups and trusts involve collaboration and partnership. ${ }^{5}$

\section{National tracker survey}

The national tracker survey is a longitudinal survey of 72 of the 481 primary care groups established in $1999 .^{6}$ The first survey was completed in December 1999 and the second in December 2000. The survey was summarised in the first article in this series. ${ }^{7}$ The evidence in this article is derived from telephone interviews with 69 of 71 chief officers of primary care groups and trusts and postal questionnaires returned by 43 of 71 representatives of social services between October and December 2000.

\section{Governance}

King's Fund, London W1M 0AN Cathy Shipman research fellow Gill Malbon research fellow

Correspondence to: C Glendinning

Caroline.

Glendinning@man. ac.uk

Series editor:

David Wilkin developments within their department or the wider local authority. However, only $27 \%$ of the representatives of social services hold formal office on primary care boards: $5 \%$ act as vice chairs and $22 \%$ as chairs or convenors of a subcommittee or working group. Social services representatives mainly are involved in subcommittees on community development $(37 \%$ of representatives), developing primary and community health services $(40 \%)$, and collaboration with local authority services (33\%). There are few representatives from other local authorities (where primary care groups and trusts cross local government boundaries), from district councils (in areas with two tier authorities), and few elected councillors participate.

\section{Developing and delivering services}

Collaborative commissioning is a key challenge for groups and trusts and one for which the benefits are clear, especially in terms of developing integrated services. Such collaboration is a radical departure from the competitive culture of the NHS's internal market.

\section{Commissioning}

A third of primary care groups and trusts still have no subgroup that handles commissioning; in those in which there is a subgroup, membership is heavily biased towards general practitioners (who are members of 94\% of commissioning groups) and community nurses (who are members of $58 \%$ of commissioning groups). Other practice staff, community health service managers, clinicians, acute care staff, other health professionals, and lay people are even less well represented. Only two fifths of commissioning subgroups include a representative from social services.

Consultations to inform commissioning decisions are also largely held with primary care and community

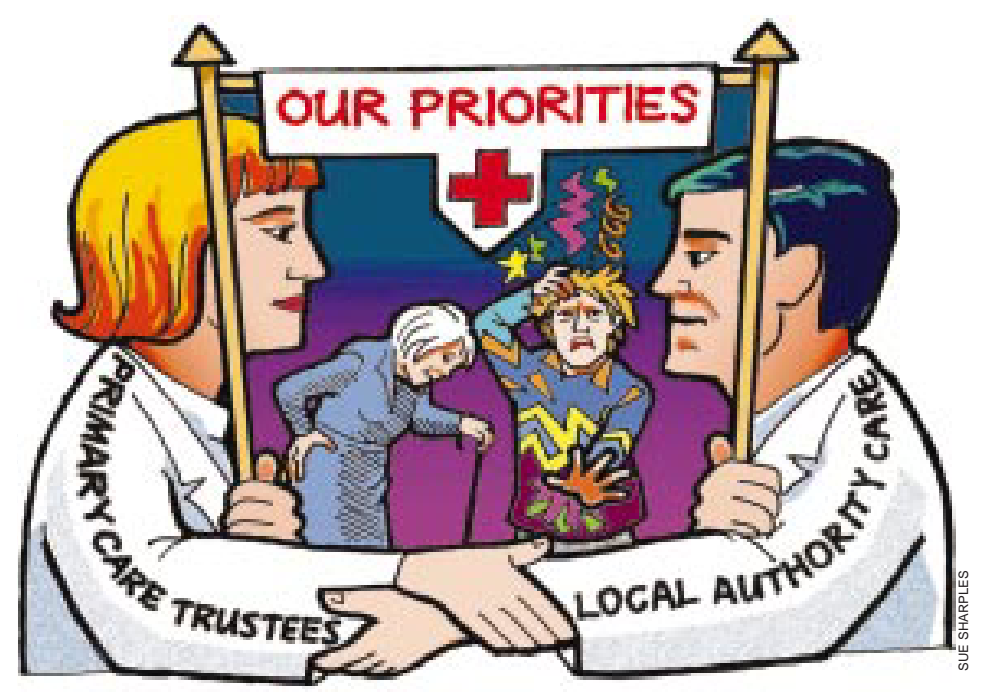




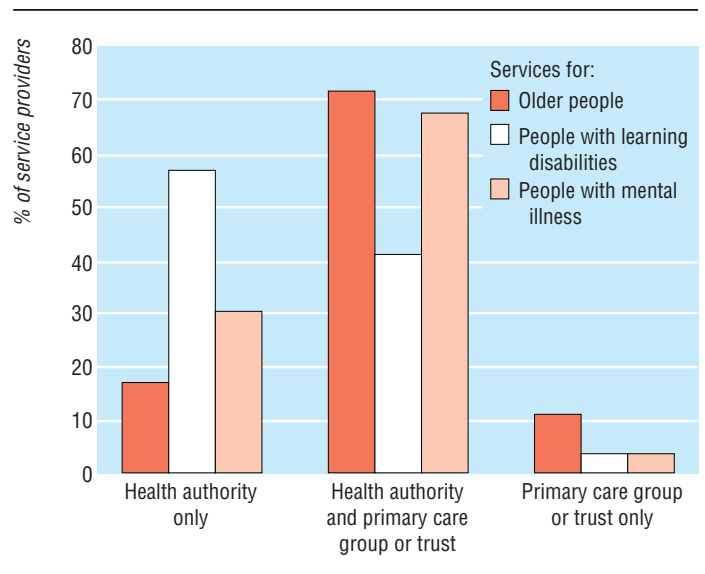

Responsibilty for commissioning

Percentage of organisations responsible for commissioning services for older people, people with learning disabilities, and people with mental illness, according to the primary care groups and trusts surveyed

health professionals, although two thirds of groups and trusts consulted hospital doctors and nurses about commissioning acute services. Representatives from social services were more likely to be consulted about commissioning community health services than about acute health services, but nearly half of the groups and trusts surveyed reported that they had not consulted any representatives from social services.

In contrast, collaboration with other groups and trusts was widespread, with all chief officers reporting some kind of collaboration in commissioning hospital services, and most groups collaborated in commissioning community health services, presumably from the same providers.

\section{Joint commissioning with social services}

The NHS plan emphasises that social services departments are key partners for groups and trusts and that collaborative performance will be closely scrutinised. However, in most groups and trusts the responsibility for jointly commissioning services for older people and for those who are mentally ill is still shared with the health authority; only $11 \%$ of primary care groups and trusts have taken over all responsibility for jointly commissioning services for older people (figure).

Joint investment plans-under which the needs of and services for older people, people with mental illness, and groups of disabled people are reviewed by health and social services authorities togetherprovide a specific focus for joint commissioning. A third of board members with primary responsibility for commissioning reported working on a joint investment plan during the past year; this is an increase from $16 \%$ in the first year. Just over two thirds expected that their group or trust would take more responsibility for the joint investment plan in the coming year.
Making shared decisions about investing one partner's resources requires trust between partners. A further indicator of robust commissioning partnerships, therefore, is the extent to which groups and trusts collaborate in investing resources from social services that have been specifically earmarked for developing partnerships. Altogether, $88 \%$ of groups and trusts were using partnership grants; $90 \%$ were using prevention grants; and $75 \%$ were using the carers' grant. These were all modest increases from a year earlier.

When asked to identify their priorities for working in partnership with social services, $91 \%$ of chief officers cited the need to address services for older people (also a key priority in the NHS plan); $58 \%$ cited mental health services for adults; and 35\% cited services for families and children. Specific strategies developed to provide services for older people-including providing rehabilitation in the community, intensive care and 24 hour rapid response home care, and joint assessments (table)-reflected the priorities set out in the NHS plan.

\section{Improving collaboration on the front line}

These slowly developing partnerships were reflected in reports of improved collaboration among staff in social services, general practices, and community health services. According to representatives from social services, relationships between social workers and general practitioners have improved greatly in over a third of primary care groups and trusts, and they have improved a little in a further half. Similar improvements have been reported in relationships between social services staff and community health staff. Joint training of NHS staff and local authority staff had taken place during the past year in $64 \%$ of groups and trusts, and more training was planned in a third.

\section{Wider partnership networks}

Beyond their relations with social services departments, there was considerable variation in the effectiveness of the networks formed by groups and trusts with their wider local authorities' services. Partnerships with private sector organisations were comparatively common, with $59 \%$ of groups and trusts involved in joint initiatives. The most common partners from the private sector were pharmaceutical companies, organisations that provided community services such as physiotherapy, and independent providers of long term or residential care. Participation in multiagency initiatives, such as local regeneration projects or leisure and recreation developments, was also relatively common. Additionally, the proportion of groups and trusts contributing resources to non-NHS initiatives that addressed leisure, community development, or support for carers, had doubled over the past year, from $48 \%$ to $81 \%$. Almost half of the primary care groups and trusts surveyed were contributing to at least three such initiatives.

Priorities for developing services for older people in partnerships between primary care groups or trusts and social services

\begin{tabular}{lccccc} 
& & \multicolumn{2}{c}{ Services } & \\
\cline { 2 - 6 } & Community rehabilitation & $\begin{array}{c}\text { Intensive care or 24 hour } \\
\text { rapid response home care }\end{array}$ & Intermediate care & $\begin{array}{c}\text { Support for } \\
\text { carers }\end{array}$ & $\begin{array}{c}\text { Independent living } \\
\text { equipment }\end{array}$ \\
\hline $\begin{array}{c}\text { No (\%) of groups or trusts } \\
\text { indicating priority }\end{array}$ & $19 / 40(48)$ & $16 / 40(40)$ & $12 / 40(30)$ & $12 / 40(30)$ & $12 / 40(30)$
\end{tabular}




\section{Plans, progress, opportunities, and threats}

According to the social services representatives surveyed, two thirds of the primary care groups and trusts were using or planning to use the flexibilities in the Health Act, an increase from only 13\% in the first year. This is similar to the proportion found in a recent local government association survey. ${ }^{8}$ In contrast to the priorities outlined in the NHS plan, however, the most common services covered by groups' and trusts' plans were for adults with learning disabilities or mental illness, and only half of the groups and trusts were aiming to develop integrated services for older people.

Barriers to working in partnership remain. Primary care organisations' existing interagency and interprofessional relations may be disrupted by mergers and by becoming trusts. Moreover, differences in the boundaries of primary care groups and trusts and local authority departments continue to present problems in aligning both the planning and delivery of services. Over the past year, there have been few changes in boundaries and these have been nearly as likely to increase the problems of joint working as to reduce them. Only a sixth of groups and trusts were planning to merge or become trusts because they wanted to align their boundaries more closely with those of their local authority partners. Additionally, other issues were perceived by social services representatives as barriers to partnerships; these barriers included other structural and organisational differences (for example, the perceived organisational capacity or different arrangements for accountability) and the preoccupation of primary care groups and trusts with medical issues of concern to general practitioners (for example, clinical policies or prescribing).

Overall, the capacity of groups and trusts to work in partnership is still far from developed, and more still have a long way to go before the integration envisioned in the NHS plan is achieved. The planning and commissioning of services seems particularly fragmented, with social services representatives (and many other stakeholders) remaining marginalised in the commissioning of acute care services and community health services. Joint commissioning with local authorities is still heavily supported by health authorities. These areas of activity urgently need better integration if the ambitions of the NHS plan are to be realised.

Nevertheless, primary care groups and trusts clearly recognise the need for closer collaboration, particularly with their local authority partners, in developing services for older people and for people with mental health problems. They also recognise the need for partnerships in developing a vision and formulating strategic objectives. The next stages of developing partnerships-planning detailed activities and managing operations jointly-will depend on a maturing of relations and the development of trust and increased familiarity. Such partnerships are more likely to deliver real changes than those imposed as a penalty for poor performance.

Funding: The national tracker survey is funded by the Department of Health and carried out by the National Primary Care Research and Development Centre in collaboration with the King's Fund.

Competing interests: None declared.

1 Audit Commission. A fruitful partnership: effective partnership working. London: Audit Commission, 1998.

2 Secretary of State for Health. The NHS plan: a plan for investment, a plan for reform. London: Stationery Office 2000. (Cm 4818-I.)

3 Glendinning C, Rummery K, Clarke R. From collaboration to commissioning: developing relationships between primary health and social services. BMJ 1998;317:122-5.

4 Rummery K, Glendinning C. Primary care and social services: developing new partnerships for older people. Oxford: Radcliffe Medical Press, 2000.

5 Gillam S, Abbott S, Banks-Smith J. Can primary care groups and trusts improve health? $B M J$ (in press).

6 Wilkin D, Gillam S, Leese B, eds. The national tracker survey of primary care groups and trusts: progress and challenges 1999/2000. Manchester: National Primary Care Research and Development Centre, King's Fund, 2000. (Available at www.npcrdc.man.ac.uk/pages/research/pcg.htm.)

7 Wilkin D, Gillam S, Smith K. Tackling organisational change in the new NHS. BMJ 2001;1464-7.

8 Local Government Association. Partnerships with health. A survey of local authorities. London: Local Government Association, 2000.

\section{A patient who changed my practice}

\section{It is too easy to blame only the patient}

As a trainee general practitioner in ophthalmology, I spent every Monday morning in the diabetes clinic. After five years in hospital medicine I had come to associate a fat stack of notes in young people with poorly controlled diabetes and the inevitable "you must do better or you will go blind/get renal failure/get angina/have a stroke" advice falling on deaf ears. I always felt that, no matter how I explained things, these sorts of patients either didn't understand, didn't believe me, or just didn't care.

One morning I came in and found that the set of notes on the first patient was eight inches thick; they belonged to a young lady who had had diabetes for 20 years. Looking through the notes, I saw there were numerous entries documenting high blood sugar, poor compliance with attempts to gain better control of her diabetes, a progressive decline in renal function, and extensive retinopathy.

Instead of the difficult patient I had imagined her to be, I met a charming, intelligent young lady who worked in a bank. On talking to her, it soon became apparent that she was fully aware of the implications of poor control but terrified of hypoglycaemic episodes and the disastrous effect these had had on her work in the past. Her attempts to gain better control of her diabetes had always resulted in hypoglycaemic episodes early in the morning, and she was under pressure from her manager because of all the time she had taken off work to make hospital visits. She wanted to minimise her long term complications but didn't want to lose her job.

After she left I reflected on her case. In the past, she had been asked to aim at a level of control at which the side effects were incompatible with her lifestyle; this had led to poor compliance, mutual frustration and distrust between doctor and patient, and the onset of complications. When compliance is poor we all too often blame the patient rather than look for the reasons and accept some of the blame for setting unrealistic goals.

How did this change my practice? When I meet a patient whose compliance is poor I try to remember that, although doctors are often influenced only by medical factors, patients are pulled in many different directions by social, psychological, and medical influences, and they attach priorities to these that often differ from ours. Failing to account for these differences will inevitably prevent the delivery of effective care.

R J Daniels general practice registrar, Devon 